\title{
A cost-effect analysis of an intervention against radon in homes
}

\author{
Hein Stigum $^{1}$, Terje Strand ${ }^{2}$ and Per Magnus ${ }^{1}$ \\ 1) Department of Epidemiology, Norwegian Institute of Public Health \\ 2) Norwegian Radiation Protection Authority \\ Correspondence: Hein Stigum, Norwegian Institute of Public Health, P.O. Box 4404 Nydalen, NO-0403 Oslo, Norway \\ Telephone: +4723408179 Telefax:+4723408260 E-mail: hein.stigum@fhi.no
}

\begin{abstract}
Background: Radon is a radioactive gas that may leak into buildings from the ground. Radon exposure is a risk factor for lung cancer. An intervention against radon exposure in homes may consist of locating homes with high radon exposure (above $200 \mathrm{~Bq} \mathrm{~m}^{-3}$ ) and improving these, and of protecting future houses. The purpose of this paper is to calculate the costs and the effects of this intervention. Methods: We performed a cost-effect analysis from the perspective of the society, followed by an uncertainty and sensitivity analysis. The distribution of radon levels in Norwegian homes is lognormal with mean $=74.5 \mathrm{~Bq} / \mathrm{m}^{3}$, and $7.6 \%$ above $200 \mathrm{~Bq} / \mathrm{m}^{3}$. Results: The preventable attributable fraction of radon on lung cancer was $3.8 \%(95 \%$ uncertainty interval: $0.6 \%, 8.3 \%)$. In cumulative present values the intervention would cost $\$ 238(145$, $310)$ million and save $892(133,1981)$ lives, each life saved costs $\$ 0.27(0.09,0.9)$ million. The cost-effect ratio was sensitive to the radon risk, the radon exposure distribution, and the latency period of lung cancer. Together these three parameters explained $90 \%$ of the variation in the cost-effect ratio. Conclusions: Reducing the radon concentration in present and future homes to below $200 \mathrm{~Bq} / \mathrm{m}^{3}$ will cost $\$ 0.27(0.09$, $0.9)$ million per life saved. The uncertainty in the estimated cost per life is large, mainly due to uncertainty in the risk of lung cancer from radon. Based on estimates from road construction, the Norwegian society has been willing to pay $\$ 1$ million to save a life. We therefore conclude that the intervention against radon in homes is justifiable. The willingness to pay is also larger that the upper uncertainty limit of the cost per life. Our conclusion is therefore robust against the uncertainties in the parameters.
\end{abstract}

Key words: Radon exposure, lung cancer, cost-effect analysis, attributable risk, models-mathematical

\section{INTRODUCTION}

Radon is a radioactive and chemically inert gas found in soils and rock containing radium and uranium. Radium can migrate from the ground and accumulate in buildings. The decay products of radon emit alpha particles and may lead to lung cancer when inhaled. Studies of underground miners have shown that radon exposure is a risk factor for lung cancer (Lubin et al. 1994; 1995). Case-control studies from the general population indicate a risk also at the lower radon levels found in homes (Darby et al. 1998; Pershagen et al. 1994). An earlier study has shown that the radon concentration in homes may be reduced by fairly simple, low-cost procedures (Brunsell et al. 1991). The purpose of this paper is to calculate costs and effects in terms of saved lives of an intervention against radon in Norwegian homes, and to provide uncertainty intervals for the results.

\section{MATERIALS AND METHODS}

\section{Intervention}

Intervention against radon exposure in homes begins with measuring the radon concentration in all single or semidetached houses plus all ground floor apartment houses. Homes with concentrations above $200 \mathrm{~Bq} \mathrm{~m}^{-3}$ will be improved to bring the radon level below the limit. Radon reduction will consist of ventilation, change of pressure, repairing cracks in the construction or combinations of these. The measurements will take place over a period of 10 years. As a part of the intervention, all future houses shall have radon protection integrated in the building process.

The direct costs consist of measurement, improvement and added construction costs for future houses, minus treatment costs for those that would become ill without the intervention.

The effects of the intervention are measured in saved lives. Costs and effects are calculated from the perspective of society.

\section{Model}

The number of lung cancers caused by radon exposure is calculated from the observed number of lung cancers, times the attributable fraction of lung cancers due to radon (fraction of lung cancers caused by radon exposure). The latter is calculated from the relative risk of lung cancer for a given radon level, and the number of homes with this radon level. 
The costs of the intervention are the cost of measurements, plus improvement of houses above the exposure limit plus added construction costs for future houses. The treatment costs equals the number of lung cancer cases saved, times the years of disease, times treatment costs per case. All costs and effects are discounted (converted to present values) at a value of $3 \%$ per year (Weinstein et al. 1996).

The parameter values used are given below. The model is described in full in Stigum et al. (2003).

\section{Parameter values}

Parameter values are listed in table 1, the last column shows the range used in the uncertainty analysis (see below).

The distribution of radon levels in Norwegian homes is based on two surveys by the Norwegian Radiation Protection Authority. A random sample of 7500 dwellings were measured in the period 1987 to 1989 (Strand et al. 1992). In 2000 a sample of 28810 dwellings from 114 of the 435 counties in Norway were measured. Based on this we assume an exposure distribution which is lognormal with mean $=74.5$ $\mathrm{Bq} / \mathrm{m}^{3}$, and $7.6 \%$ above $200 \mathrm{~Bq} / \mathrm{m}^{3}$. The $10 \%$ uncertainty in the $\log$ of the median $(\square)$ implies that the mean value varies from 52 to $107 \mathrm{~Bq} / \mathrm{m}^{3}$, and that the proportion above the exposure limit varies from $4 \%$ to $13 \%$.

The intervention will not remove all radon, but reduce the concentration to below the intervention level of $200 \mathrm{~Bq} / \mathrm{m}^{3}$.

Estimates of the risk of lung cancer from radon exposure are available from miner studies and from studies in homes. Linearity is based on a pooled analysis of miner data, the risk estimate is based on a metaanalysis of eight studies of residential radon exposure (Lubin \& Boice 1997) with correction for random errors in the radon exposure measures (Darby et al. 1997; Lagarde et al. 1997). Based on these considerations, the relative risk of lung cancer is assumed to increase linearly with a factor alpha $=0.0015$ (range 0.0003-0.0027) per radon level unit $\left(\mathrm{Bq} / \mathrm{m}^{3}\right)$ (Lagarde et al. 1997; Lubin et al. 1994; Lubin \& Boice 1997). This gives a relative risk of 1.15 (range 1.03-1.27) at $100 \mathrm{~Bq} / \mathrm{m}^{3}$. The large range of $\pm 80 \%$ reflects the large uncertainty in the risk estimate.

The number of measurements equals all single or semidetached houses plus all ground floor apartment houses $=1.5$ million homes (Møglestue 1994). The costs per measurement includes film and development plus a stipulated one hour work to distribute and collect the film. The costs per improvement and added new house costs are taken from an earlier work on the cost-effect of radon interventions (Brunsell et al. 1991).

The total number of lung cancers per year is taken from the Norwegian Cancer Registry 1994 data, and equals 1780 cases with an age range from 25 to 85 years and a mean age of 66 years (Anonymous 1998). Lung cancer is assumed to have a 25-year latency period followed by two years of disease (Nyberg et al. 2000). The whole intervention will run for $\square(\mathrm{tau})=10$ years. For simplicity we count all effects from five years after the start of the intervention. The time to the first saved cases is then $t s=5+25=30$ years.

The cost of treatment is taken from Norwegian hospital statistics (Ministry of Health and Social Affairs, 2000).

Table 1. Parameter values used in the cost-effect analysis of an intervention against radon exposure in homes. The symbols are from the equations in the Appendix. The uncertainty column specifies the min and max values used in the uncertainty and sensitivity analysis. Norwegian costs converted to USD.

\begin{tabular}{lcrc}
\hline Parameter & Symbol & Value & Uncertainty \\
\hline $\begin{array}{l}\text { Radon distribution } \\
\text { log(median) }\end{array}$ & & & \\
$\quad$ dispersion & & 3,64 & $\pm 10 \%$ \\
Radon risk & & 1,16 & \\
$\quad$ Risk increase per unit exposure & & 0,0015 & $\pm 80 \%$ \\
Cost related & & & \\
$\quad$ Measurements & $\mathrm{cm}$ & 1500000 & \\
$\quad$ Cost per measurement & $\mathrm{ci}$ & 20,0 & $\pm 30 \%$ \\
$\quad$ Cost per improvement & $\mathrm{br}$ & 0,015 & $\pm 30 \%$ \\
$\quad$ Building rate & $\mathrm{cn}$ & 200 & $\pm 30 \%$ \\
$\quad$ Added cost per future house & $\mathrm{ct}$ & 5000 & $\pm 30 \%$ \\
$\quad$ Cost of treatment & & & \\
Disease related & $\mathrm{ts}$ & 30 & $\pm 30 \%$ \\
$\quad$ Time to disease & $\mathrm{y}$ & 2 & $\pm 30 \%$ \\
$\quad$ Years of disease & & & \\
Other & $\mathrm{L}$ & 200 & \\
$\quad$ Exposure limit, Bq $\mathrm{m}^{-3}$ & $\mathrm{~d}$ & 0,03 & \\
$\quad$ Discount rate & & & \\
\hline
\end{tabular}


The radon exposure limit is $200 \mathrm{~Bq} / \mathrm{m}^{3}$. The discount rate is $3 \%$ per year following the recommendations from the Panel on Cost-Effectiveness in Health and Medicine (Russell et al. 1996; Siegel et al. 1996; Weinstein et al. 1996). Costs were converted from Norwegian kroner assuming 9.5 NOK per US\$ and then rounded.

\section{Uncertainty and sensitivity analysis}

The uncertainty of each parameter is described by a probability distribution (a beta distribution with shape parameters 2 and 2) with minimum and maximum values equal to the parameters value plus/minus the percentages shown in table 1 . The simultaneous uncertainty of the parameters leads to an uncertainty in the output measures, which can be expressed in an interval given by the upper and lower $2.5 \%$ fractiles of the output distributions. We term this a $95 \%$ uncertainty interval.

The sensitivity analysis finds parameters with high influence on the output uncertainty. The method is explained in Stigum et al. (2003).

\section{SIMPLIFIED CALCULATION}

The full model for the cost-effect calculation is fairly complex. We therefore start out with a simplified calculation to show the main reasoning of the model. In the simplified calculation we will not use discounting, instead we look at costs and effects over the next 40 years after the intervention.

To measure radon in 1.5 million houses for $\$ 20$ each will cost $\$ 30$ million. If $7 \%$ of houses need radon improvement for $\$ 700$ each, the cost will be $\$ 75$ million. If $0.015 \times 1.5 \times 10^{6}$ houses are replaced per year with $\$ 200$ in extra radon protection cost, then over the next 40 years this will cost $\$ 180$ million. In sum the intervention will cost $\$(30+75+180)=\$ 285$ million. For simplicity we ignore the treatment costs that could be saved by the intervention.

If the relative risk of lung cancer from radon increases linearly with a factor 0.0015 per radon unit, then we expect to save 0.0015 of the 1800 observed lung cancer cases $=2.7$ cases each year for each unit we decrease the mean radon level. If we remove all radon from houses with levels above $200 \mathrm{~Bq} / \mathrm{m}^{3}$, the mean radon level will decrease with about $30 \mathrm{~Bq} / \mathrm{m}^{3}$, and we will save 2.7 cases $\mathrm{x} 30=81$ cases each year. With a latency period of 30 years for lung cancer, we will over the 40 years after intervention save 81 lives $\mathrm{x}$ $10=810$ lives.

The cost of saving one life is then $\$ 285 / 810=\$ 0.35$ million. We stress that this is based on a simplified calculation that disregards many of the elements in the full cost-effect analysis below.

\section{RESULTS}

\section{Full cost-effect analysis}

The total attributable fraction of radon on lung cancer is calculated to be $11.2 \%$, the preventable attributable fraction is $3.8 \%$. The main results of the full costeffect analysis are shown in table 2 .

Radon measurements will cost $\$ 3$ million each year over a period of 10 years, giving a cumulative present value of \$26 million (the discounting implies less weight on future costs, hence the present value is less than $\$ 3 \times 10$ million). Improvement of houses above the exposure limit will cost $\$ 8$ million per year, in sum $\$ 69$ million. Added costs in future houses will cost $\$ 4.5$ million each year, giving a cumulative present value of $\$ 152$ million. Saved treatment costs come to $\$ 0.7$ million per year, in sum $\$ 9.5$ million. Total direct costs equal $\$(26+69+152-9.5)=\$ 238$ million. We see that the added cost to the construction of future houses dominates the costs because these costs run over a long time period.

After the latency period the intervention will save 68 lives each year, giving a cumulative total of 892 lives saved. The intervention will save 15,590 life years (see Stigum et al. (2003) for calculation), upon division we find that each life contributes on average 17.5 years. This is a substantial extension of life, therefore counting lives saved gives a meaningful interpretation of the results (Nord 1999).

Table 2. Cost-effect analysis of an intervention against radon exposure in homes. Columns contain time period, value per year, and cumulative present value discounted at $3 \%$ per year. Costs in million USD.

\begin{tabular}{|c|c|c|c|c|}
\hline & \multicolumn{2}{|c|}{ Period } & \multirow{2}{*}{$\begin{array}{r}\text { Per year } \\
\text { in period }\end{array}$} & \multirow{2}{*}{$\begin{array}{r}\text { Cumulative } \\
\text { present value }\end{array}$} \\
\hline & from & to & & \\
\hline \multicolumn{5}{|l|}{ Direct costs } \\
\hline Measurement & 0 & 10 & 3,0 & 26,0 \\
\hline Improvement & 0 & 10 & 8,0 & 69,2 \\
\hline Added costs in future houses & 0 & - & 4,5 & 152,2 \\
\hline Treatment & $t_{s}$ & - & 0,7 & 9,5 \\
\hline \multicolumn{5}{|l|}{ Effects } \\
\hline Lives & $t_{d}$ & - & 68 & 892 \\
\hline $\begin{array}{l}\text { Direct cost-effect ratio } \\
\text { Cost per life }\end{array}$ & & & & 0,267 \\
\hline
\end{tabular}


When we invest \$238 million to save 892 lives, each life saved costs $\$ 0.27$ million. The costs per life year saved are $\$ 15000$.

\section{Uncertainty and sensitivity results}

The fraction of lung cancer cases due to radon has an uncertainty interval from $2.1 \%$ to $21 \%$, whereas the preventable fraction has an uncertainty interval from $0.6 \%$ to $8.3 \%$, table 3 .

Table 3. Estimate with $95 \%$ uncertainty interval based on the uncertainty analysis, of the attributable fractions, the cumulative present value of direct costs and saved lives, and the direct cost effect ratios. Costs in million USD.

\begin{tabular}{lrc}
\hline & Median & $\begin{array}{c}\text { 95\% uncertainty } \\
\text { interval }\end{array}$ \\
\hline Attributable fraction & & \\
$\quad$ Total & $11,0 \%$ & $(2,1 \%, 20,7 \%)$ \\
$\quad \begin{array}{l}\text { Preventable } \\
\text { Costs and effects } \\
\quad \text { Directs costs }\end{array}$ & $3,7 \%$ & $(0,6 \%, 8,3 \%)$ \\
$\quad$ Lives & 238 & $(145,310)$ \\
$\begin{array}{l}\text { Direct cost-effect ratio } \\
\quad \text { Cost per life }\end{array}$ & 858 & $(133,1981)$ \\
\hline
\end{tabular}

The direct cost has an uncertainty interval from $\$ 145$ to $\$ 310$ million. The number of lives saved by the intervention has an uncertainty interval from 133 to 1981 lives, note also that the median number of lives saved is slightly less than the direct estimate in table 2 . The direct cost-effect ratio has an uncertainty interval from $\$ 0.09$ to $\$ 0.9$ million per life saved. We see that the uncertainty in the effects is much larger than in the costs, the upper limit is about two times the lower limit for the costs, but almost 15 times for the saved lives.

The sensitivity of a parameter is measured by the amount of variation in the output explained by the variation in the parameter. The direct cost per life was above all sensitive to the radon risk measure $(\square)$, table 4. It was also sensitive to the log of the median of the radon exposure distribution $(\square)$, and the latency period (ts). Together the variation in these parameters account for $90 \%$ of the variation in the cost per life.

\section{DISCUSSION}

Based on the calculation in this paper we found that the preventable attributable fraction of radon on lung cancer was $3.8 \%$ (95\% uncertainty interval: $0.6 \%$, $8 \%$ ). In cumulative present values the intervention would cost $\$ 238(145,310)$ million and save 892 (133, 1981) lives, each life saved costs $\$ 0.27(0.09,0.9)$ million. The cost-effect ratio is sensitive to the radon risk, the radon exposure distribution, and the latency period of lung cancer. It also depends on the choice of discount rate.

The cost-effect analysis is done from the perspective of society. Its aim is to calculate the total costs of reducing radon levels in present and future homes to below the exposure level, and to calculate the lives saved from this. We do not differentiate between costs covered by private or government sources.

The estimated cost-effect may either be compared to measures of willingness to pay derived from other studies, or to cost-effect measures from other types of interventions. Based on estimates from road construction, the Norwegian society has been willing to pay $\$ 1$ million to save a life (Elvik 1993). The cost per life is considerable less than the $\$ 9$ million estimated for testing blood donors for HTLV (Stigum et al. 2000).

The estimated cost-effect ratio has a large uncertainty, mainly due to the uncertainty in the radon risk estimate. The estimate is based on results from a pooled analysis of miners, from a metaanalysis of eight home studies, and from two papers describing the effect of random error in the radon exposure (Darby et al. 1997; Lagarde et al. 1997; Lubin et al. 1995; Lubin \& Boice 1997). The pooled miner data have the advantage of being cohort studies with large numbers (65 000 subjects and 2700 lung cancer deaths). We base our assumption of a linear relationship between exposure and risk on this data. To use

Table 4. Standardised regression coefficients and explained variance for the association between the direct cost per life and each parameter based on multiple linear regression.

\begin{tabular}{llrr}
\hline Parameter & Parameter interpretation & $\begin{array}{r}\text { Standardised } \\
\text { correlation } \\
\text { coefficient }\end{array}$ & $\begin{array}{r}\text { Explained } \\
\text { variance }\end{array}$ \\
\hline \hline & Slope of radon risk & $-0,82$ & $67 \%$ \\
$\square$ & Log median radon exposure & $-0,41$ & $17 \%$ \\
ts & Latency period of lung cancer & 0,25 & $6 \%$ \\
cn & Added cost in future houses & 0,16 & $3 \%$ \\
br & Building rate & 0,16 & $3 \%$ \\
ci & Cost per improvement & 0,07 & $0 \%$ \\
yd & Expected years of disease & 0,01 & $0 \%$ \\
ct & Cost of treatment & 0,00 & $0 \%$ \\
cm & Cost of measurement & 0,03 & $0 \%$ \\
\hline
\end{tabular}


this data to calculate radon risk in homes however requires many extra assumptions. The risk estimate must be extrapolated to levels about $1 / 20$ of the miner levels. One must use a correction factor to account for reduced delivery of dose in homes. One must assume an average number of hours spent at home per day and an expected number of years in the home. We therefore prefer to base our estimate on the case control studies from homes. These studies have the advantage of calculating the risk in homes directly. But measuring exposure correctly is problematic in these studies. It requires measuring the radon level in all the homes that each case or control has inhabited over lifetime, thus many measurements are done years after the exposure took place, and are therefore unprecise. Exposure measurement errors are expected to lower the risk estimates (bias the risk towards the null) for a wide range of assumptions about the error structure (Lagarde et al. 1997). Two groups have modelled the bias using a simple error structure, that is, assuming that the measured exposure is equal to the true exposure times an error term with lognormal $\left(0, \square^{2}\right)$ distribution. Using a coefficient of variation $(\mathrm{cov}=\square /$ true exposure) of $50 \%$ as found in a dataset with repeated measurements, they found that the risk estimate should be increased by a factor of 1.5 or more (Darby et al. 1997; Lagarde et al. 1997). Our risk estimate is based on the home studies with this type of correction for exposure error. Without correction using $\square=0.001$ $\left(\mathrm{RR}=1.10\right.$ at $\left.100 \mathrm{~Bq} / \mathrm{m}^{3}\right)$, the preventable attributable fraction is $2.6 \%$ and the cost per life equals $\$ 0.40$ million.

The effect of smoking on lung cancer is not explicitly included in the model. We assume that the distri- butions of radon and smoking are independent, and that smoking and radon has an multiplicative effect on lung cancer risk. The attributable risk of radon on lung cancer will then be the same among smokers and nonsmokers, and we do not need to stratify on smoking in the model.

Most of the lung cancer cases will occur among smokers. For a relative risk of 10 and $40 \%$ smokers, $75 \%$ of the cases will be among smokers. The life expectancy among smokers is about eight years less than for non-smokers (Doll et al. 1994), so the number of life years saved per life should be closer to 14 rather than the estimated 17.5 years. This is still a substantial extension of life; therefore, counting lives saved still gives a meaningful interpretation of the results.

It is assumed that all homes with ground floor shall be measured. It may be possible to use a two-step measuring strategy to reduce number of measurements and thereby reduce the costs.

\section{CONCLUSION}

Reducing the radon concentration in present and future homes to below $200 \mathrm{~Bq} / \mathrm{m}^{3}$ will cost $\$ 0.27(0.09,0.9)$ million per life saved. The uncertainty in the estimated cost per life is large, mainly due to uncertainty in the risk of lung cancer from radon. Based on estimates from road construction, the Norwegian society has been willing to pay $\$ 1$ million to save a life. We therefore conclude that the intervention against radon in homes is justifiable there. The willingness to pay is also larger that the upper uncertainty limit of the cost per life. Our conclusion is therefore robust against the uncertainties in the parameters.

\section{REFERENCES}

Anonymous, 1998. Cancer in Norway 1995, The Cancer Registry of Norway.

Brunsell JT, Hustoft AG, Lind B, Strand T, 1991. Radon i eksisterende boliger, Byggforsk rapport, vol. 86.

Darby S, Whitley E, Silcocks P, et al., 1998. Risk of lung cancer associated with residential radon exposure in south-west England: a case-control study. Br J Cancer 78 (3): 394-408.

Darby SC, Whitley E, Reeves GK, 1997. The importance of accounting for uncertainties in the determination of radon concentrations in studies of the carcinogenic effects of residential radon exposure. Health effect of low dose radiatio, pp. 96-99. BNES, London

Doll R, Peto R, Wheatley K, Gray R, Sutherland I, 1994. Mortality in relation to smoking: 40 years' observations on male British doctors. BMJ $\mathbf{3 0 9}$ (6959): 901-911.

Elvik R, 1993. How much are avoided traffic accidents worth to society? Summary report. [Hvor mye er unngåtte trafikkulykker verd for samfunnet? Oppsummeringsrapport] Transportøkonomisk institutt, Oslo.

Lagarde F, Pershagen G, Akerblom G, et al., 1997. Residential radon and lung cancer in Sweden: risk analysis accounting for random error in the exposure assessment. Health Phys 72 (2): 269-276.

Lubin JH, Boice JD, Jr, 1997. Lung cancer risk from residential radon: meta-analysis of eight epidemiologic studies, J Natl Cancer Inst 89 (1): 49-57.

Lubin JH, Boice JD, Jr, Edling C, 1994. Radon and lung cancer risk. A joint analysis of 11 underground miner studies. NIH Publ, vol. 94.

Lubin JH, Boice JD, Jr, Edling C, et al., 1995. Lung cancer in radon-exposed miners and estimation of risk from indoor exposure. J Natl Cancer Inst 87 (11): 817-827. 
Ministry of Health and Social Affairs (Norway). Diagnose Related Groups, hospital costs 2000 [Prisliste DRG 2000]. [http://odin.dep.no/shd/proj/isf/2000/prislistedrg/, 2000]

Møglestue I, 1994. Statistical yearbook. Statistics Norway, Oslo.

Nord E, 1999. Cost-value analysis in health care. Cambridge University Press, New York.

Nyberg F, Gustavsson P, Järup L, Bellander T, Berglind N, Jacobsson R, Pershagen G, 2000. Urban air pollution and lung cancer in Stockholm. Epidemiology 11 (5): 487-495.

Pershagen G, Akerblom G, Axelson O, et al., 1994. Residential radon exposure and lung cancer in Sweden. $N$ Engl J Med 330 (3): 159-164.

Russell LB, Gold MR, Siegel JE, Daniels N, Weinstein MC, 1996. The role of cost-effectiveness analysis in health and medicine. Panel on Cost-Effectiveness in Health and Medicine. JAMA 276 (14): 1172-1177.

Stigum H, Magnus P, Samdal HH, Nord E, 2000. Human T-cell lymphotropic virus testing of blood donors in Norway, a cost-effect model. Int J Epidemiol 29: 1076-1084.

Stigum H, Strand T, Magnus P, 2003. Should radon be reduced in homes? A cost effect analysis. Health Phys 84: 227-235.

Strand T, Green BM, Lomas PR, 1992. Radon in Norwegian dwellings. Rad Prot Dos 45: 503-508.

Weinstein MC, Siegel JE, Gold MR, Kamlet MS, Russell LB, 1996. Recommendations of the Panel on Costeffectiveness in Health and Medicine. JAMA 276 (15): 1253-1258. 